\title{
Lumbar pseudarthrosis: a review of current diagnosis and treatment
}

\author{
Danielle S. Chun, BA, ${ }^{1}$ Kevin C. Baker, PhD, ${ }^{2}$ and Wellington K. Hsu, MD1 \\ 'Department of Orthopaedic Surgery, Northwestern University Feinberg School of Medicine, Chicago, Illinois; and '2Department \\ of Orthopaedic Surgery, William Beaumont Hospital, Royal Oak, Michigan
}

\begin{abstract}
OBJECT Failed solid bony fusion, or pseudarthrosis, is a well-known complication of lumbar arthrodesis. Recent advances in radiographic technology, biologics, instrumentation, surgical technique, and understanding of the local biology have all aided in the prevention and treatment of pseudarthrosis. Here, the current literature on the diagnosis and management of lumbar pseudarthroses is reviewed.
\end{abstract}

METHODS A systematic literature review was conducted using the MEDLINE and Embase databases in order to search for the current radiographic diagnosis and surgical treatment methods published in the literature (1985 to present). Inclusion criteria included: 1) published in English; 2) level of evidence I-III; 3) diagnosis of degenerative lumbar spine conditions and/or history of lumbar spine fusion surgery; and 4) comparative studies of 2 different surgical techniques or comparative studies of imaging modality versus surgical exploration.

RESULTS Seven studies met the inclusion criteria for current radiographic imaging used to diagnose lumbar pseudarthrosis. Plain radiographs and thin-cut CT scans were the most common method for radiographic diagnosis. PET has been shown to be a valid imaging modality for monitoring in vivo active bone formation. Eight studies compared the surgical techniques for managing and preventing failed lumbar fusion. The success rates for the treatment of pseudarthrosis are enhanced with the use of rigid instrumentation.

CONCLUSIONS Spinal fusion rates have improved secondary to advances in biologics, instrumentation, surgical techniques, and understanding of local biology. Treatment of lumbar pseudarthrosis includes a variety of surgical options such as replacing loose instrumentation, use of more potent biologics, and interbody fusion techniques. Prevention and recognition are important tenets in the algorithm for the management of spinal pseudarthrosis.

http://thejns.org/doi/abs/10.3171/2015.7.FOCUS15292

KEY WORDS lumbar pseudarthrosis; spine fusion; lumbar surgery

$\mathrm{L}$ UMBAR arthrodesis is a commonly indicated treatment for infection, tumor, trauma, deformity, and degenerative diseases of the spine. With broad indications and continuing improvements in surgical technology, there has been an increase in the rate of lumbar spine fusions performed over the last few decades. ${ }^{17,24,26,52,59} \mathrm{Un}$ fortunately, these procedures can lead to failed solid bony fusion, or pseudarthrosis, which is a well-known iatrogenic complication. The rates of pseudarthrosis after lumbar spine fusions have ranged from 5\% to $35 \%$, $3,16,27,31$ with a significantly higher incidence in those spanning 3 or more spinal levels. ${ }^{13}$
In 1991, Heggeness and Esses ${ }^{30}$ described 4 unique morphological categories to help classify posterolateral lumbar pseudarthroses: atrophic, transverse, shingle, and complex (Fig. 1). Despite this, it is often difficult to predict when or if a pseudarthrosis will become symptomatic for the patient. ${ }^{44,52}$ DePalma and Rothman ${ }^{16}$ retrospectively compared outcomes in patients with radiographic evidence of lumbar pseudarthrosis to a matched cohort with successful lumbar fusion. They found no significant difference between the 2 groups with regard to return to activity, symptom relief, and subjective satisfaction with the surgery. 

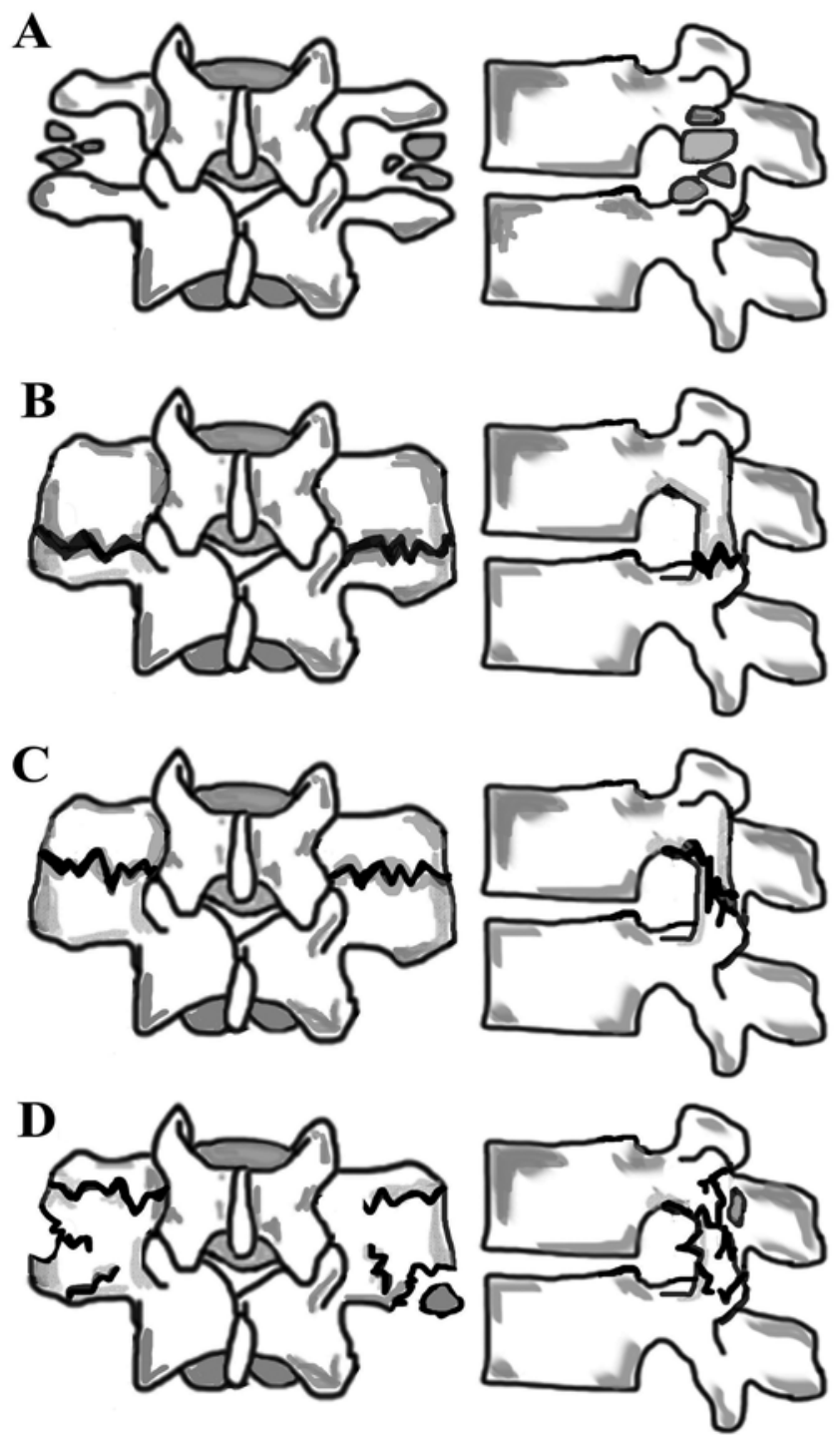

FIG. 1. Heggeness and Esses' morphological classification of posterolateral lumbar pseudarthrosis. A: Atrophic. B: Transverse. C: Shingle. D: Complex. Copyright Danielle Chun. Published with permission.

However, more recent studies suggest that successful lumbar fusion correlates with long-term improved functional outcomes and decreased symptom severity. ${ }^{40}$ Kornblum et al. reported that among their patients with symptomatic spinal stenosis and spondylolisthesis treated with bilateral posterolateral arthrodesis, $86 \%$ of the patients with solid arthrodesis had "excellent" or "good" long-term clinical outcome compared with $56 \%$ of patients with a pseudarthrosis. However, in clinical situations that require a revision spinal fusion for pseudarthrosis, Carpenter et al. reported that only $26 \%$ (19 of 72 patients) had excellent or good operative outcomes, despite the fact that solid fusion was achieved in $94 \%$ of the total cohort. ${ }^{10}$

It remains unclear why some cases of pseudarthrosis remain asymptomatic with excellent long-term clinical outcomes, while others require significant management and treatment. ${ }^{1,10}$ While bony nonunion can be asympto- matic on short-term follow-up, this condition can lead to reoperations up to 10 years after the index procedure. . $9,40,48^{-1}$

Given the rising number of lumbar fusions performed, it is important that the surgeon and patient be aware of the diagnosis, prevention, and treatment of this complication. This article will review the current diagnostic and management approaches to lumbar pseudarthroses. Furthermore, we will briefly discuss promising areas of research in the treatment and prevention of failed spinal fusion.

\section{Methods}

A systematic literature search using the MEDLINE and Embase databases was conducted for articles published in the English language from 1985 to the present with a combination of the keywords "pseudarthrosis" AND "lumbar" and 1 of the following words: "plain radiograph" OR "tomography, X-Ray computed" OR "magnetic resonance imaging" OR "radionuclide imaging" OR "positron-emission tomography." To identify literature comparing different surgical techniques, the following keywords were used: "fusion rate" AND "interbody fusion" AND "lumbar." Finally, a hand-search strategy using the pertinent references from the selected articles and other systematic reviews and guidelines was conducted.

All abstracts from the query results were reviewed for the inclusion criteria (Figs. 2 and 3). The criteria for study inclusion are as follows. For all studies: clinical studies with level of evidence I-III; adult patients with a minimum age of 18 years; and minimum of 1-year of radiographic follow-up. For studies focusing on radiographic diagnostic modalities, additional inclusion criteria were: diagnosis of suspected lumbar pseudarthrosis after lumbar spinal fusion; reported sensitivity and specificity of the imaging modality; and studies correlating radiographic findings to surgical exploration. For studies focusing on the fusion surgical technique, additional inclusion criteria were: diagnosis of a degenerative lumbar spine condition (e.g., degenerative disc disease) and studies comparing the fusion rates of 2 or more surgical techniques.

\section{Results}

\section{Imaging Modalities}

Forty-five articles were found using the Embase and MEDLINE Ovid database. Five articles were excluded because they were published in the non-English language literature and during an incorrect time frame, and 4 articles were excluded because they were animal studies. Thirtysix articles were then reviewed for inclusion and exclusion criteria. A total of 7 articles were included that compared the utility of imaging modalities and surgical exploration for the diagnosis of lumbar pseudarthrosis. Of these, 2 studies examined the utility of plain radiographs, ${ }^{7,37} 2$ studies examined the utility of $\mathrm{CT}^{7,42} 2$ studies examined the utility of bone scintigraphy, ${ }^{2,6}$ and 1 study examined the utility comparing all 3 types of imaging modalities. ${ }^{45}$

Plain radiography is commonly used for the initial assessment of pseudarthrosis and other possible diagnoses given its widespread availability and relative low cost. However, the time to the radiographic presentation of pseudarthrosis can vary. Using plain radiographs, Kim 


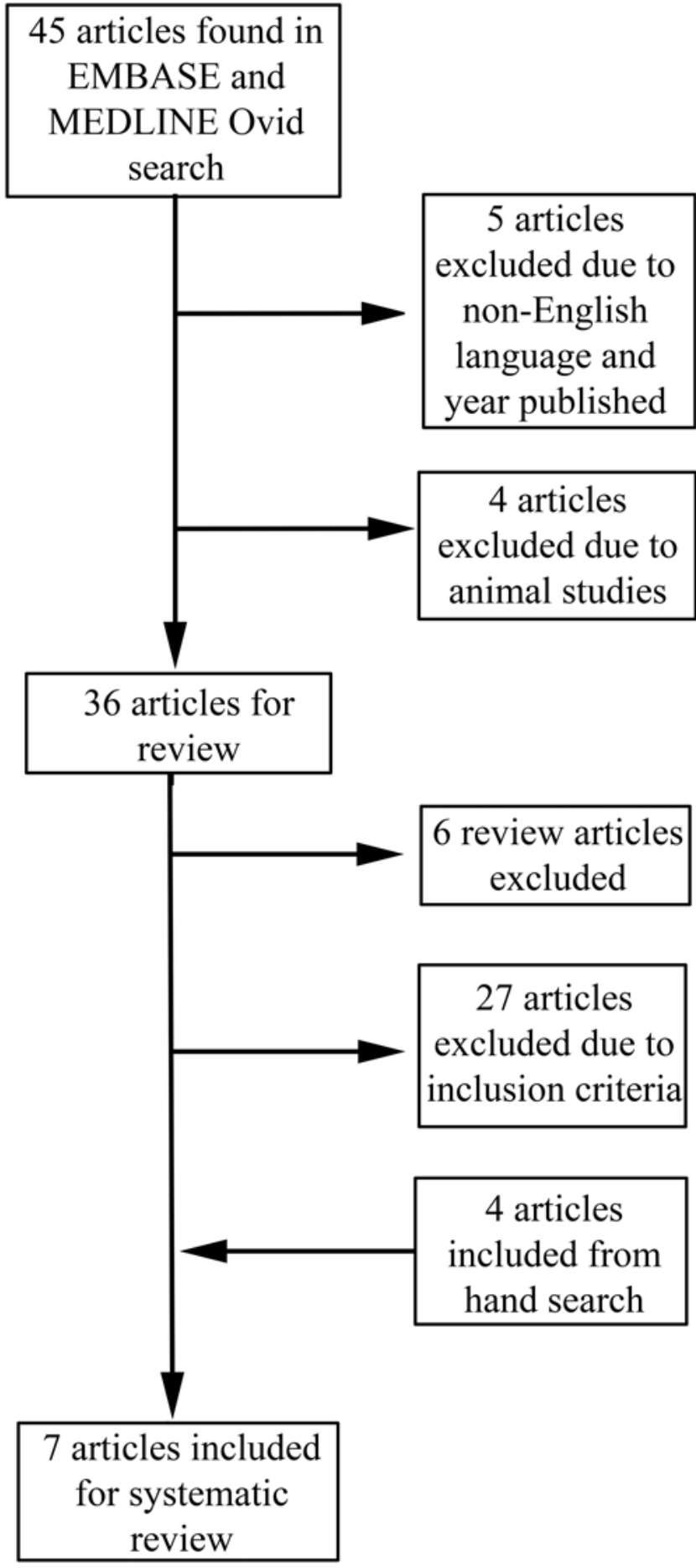

FIG. 2. Flowchart illustrating the methodology for identifying relevant articles comparing various imaging modalities used for the diagnosis lumbar pseudarthrosis.

et al. found an average time of 3.5 years (range 12-131 months) before the detection of pseudarthrosis using plain radiographs. ${ }^{39}$ Similarly, Dickson et al. reported that of 18 pseudarthrosis complications, only 13 (72\%) were detected radiographically within the first 2 years postoperatively. ${ }^{18}$ These findings demonstrate that the annual radiographic follow-up should be implemented for multilevel

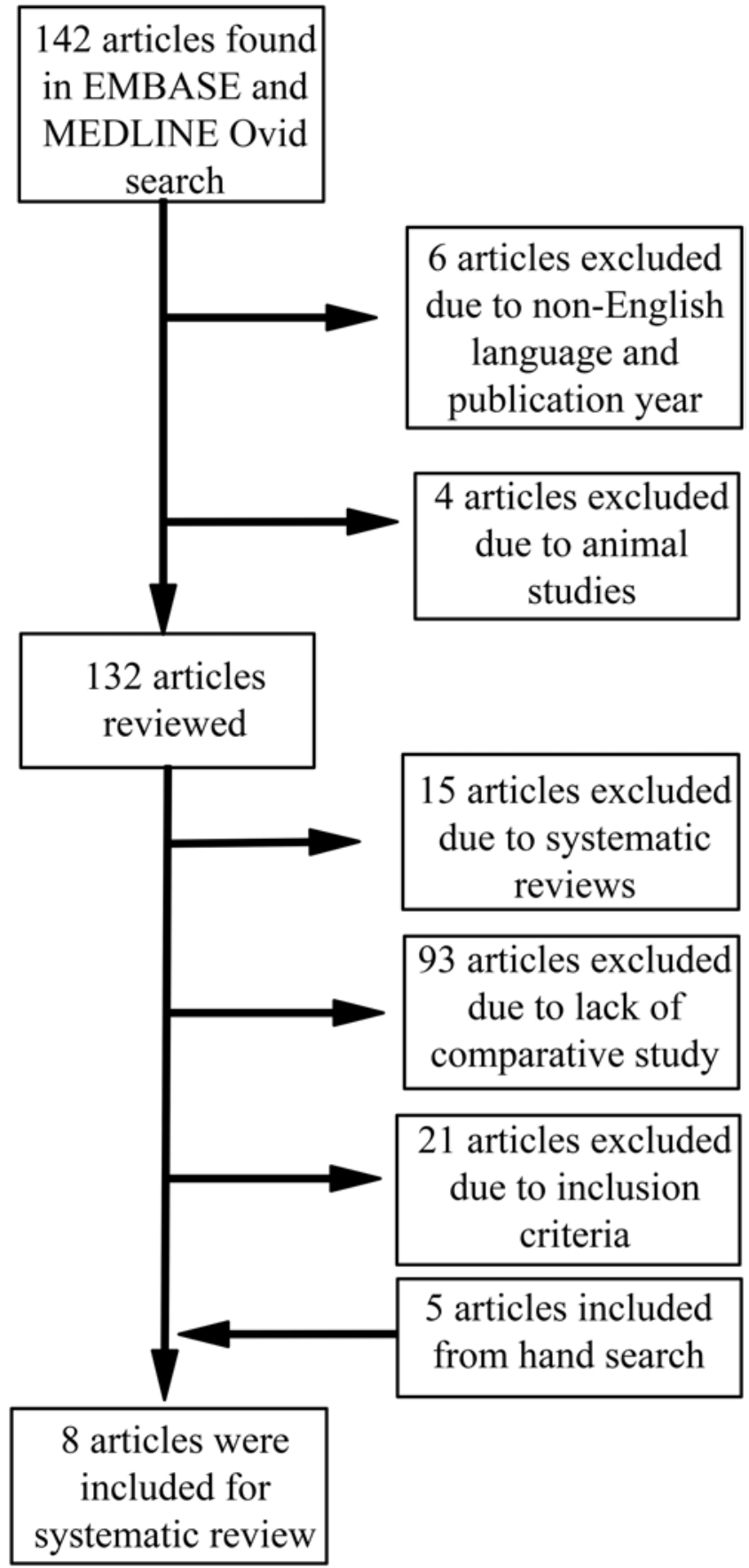

FIG. 3. Flowchart illustrating the methodology for identifying relevant articles comparing surgical fusion techniques.

fusions, even if bony union is proven at an early time point (Table 1).

While static views can appreciate bony mass within the surgical site, false negatives for a solid bony fusion can be high. ${ }^{11}$ Brodsky et al. demonstrated a $64 \%$ correlation rate between preoperative anteroposterior and lateral plain radiographs and surgical exploration, with plain radiography demonstrating $89 \%$ sensitivity and $60 \%$ specificity for predicting solid bone fusion. ${ }^{7}$ Similarly, Kant et al. reported a $68 \%$ correlation rate between static plain radio- 
TABLE 1. Comparison of radiographic modalities for detecting lumbar fusion

\begin{tabular}{llccc}
\hline \multicolumn{1}{c}{ Authors \& Year } & Imaging Modality & Sensitivity & Specificity & Correlation w/ Surgical Finding \\
\hline Brodsky et al., 1991 & Plain radiography & $89 \%$ & $60 \%$ & $64 \%$ \\
& CT & $63 \%$ & $86 \%$ & $57 \%$ \\
\hline Kant et al., 1995 & Plain radiography & $85 \%$ & $62 \%$ & $68 \%$ \\
\hline Laasonen \& Soini, 1989 & CT & - & - & $78 \%$ \\
\hline Albert et al., 1998 & SPECT & $50 \%$ & $58 \%$ & \\
\hline Bohnsack et al., 1999 & Bone scintigraphy & $50 \%$ & $93 \%$ & $62 \%$ \\
\hline Larsen et al., 1996 & Plain radiography & $42 \%$ & $89 \%$ & $63 \%$ \\
& CT & $53 \%$ & $86 \%$ & $60 \%$ \\
\hline
\end{tabular}

graphs and intraoperative findings (plain radiographs had $85 \%$ sensitivity and $62 \%$ specificity). ${ }^{37}$

CT imaging has the strongest correlation with the intraoperative assessment of fusion status.,22 While there are no universally accepted criteria for assessing interbody bone fusion, most studies use all or some of the following features for defining pseudarthrosis: complete absence of continuous bony trabeculation between adjacent vertebrae, peri-implant radiolucency, and/or motion on dynamic films. ${ }^{35,56,57}$

Early studies using CT scans have shown $57 \%$ to $80 \%$ correlation between fusion assessments based on imaging versus intraoperative findings, with $53 \%$ to $63 \%$ sensitivity and $78 \%$ to $86 \%$ specificity. ${ }^{7,42,54}$ Since then, there have been considerable advancements in CT technology with the introduction of thin-section axial sequencing and 3D imaging (Fig. 4). ${ }^{43}$ Kanemura et al. used thin-section helical CT scans to demonstrate longitudinal radiographic changes in patients with pseudarthrosis after posterior or transforaminal lumbar interbody arthrodesis. Based on the results of 5-year follow-up examinations, they reported that a radiolucent zone of more than $1 \mathrm{~mm}$ around the interbody cage at the 12-month mark was shown to be an early predictor of permanent pseudarthrosis in their cohort. ${ }^{35}$ Similarly, Shah et al. ${ }^{56}$ reported that bridging trabeculation was appreciated on $95 \%$ of CT scans $(\kappa=0.85)$ versus $4 \%$ on plain films $(\kappa=0.74)$ for patients with lumbar interbody fusion. Based on these findings, the authors also suggest that thin-section CT scans should be the modality of choice for the early detection of pseudarthrosis.

Bone scintigraphy uses a radiographic tracer-commonly ${ }^{99 \mathrm{~m} T c-l a b e l e d}$ diphosphonate-to localize tissue with high metabolic activity (indicating acute tissue changes and/or repair). While its use is currently indicated for diagnosing bone infections, neoplasms, and occult fractures, ${ }^{33}$ it remains a poor choice for the detection of spine pseudarthroses due to poor sensitivity. Bohnsack et al. reported only $50 \%$ sensitivity and $93 \%$ specificity with the use of ${ }^{99 \mathrm{~m} T c .}{ }^{6}$ Similarly, McMaster and Merrick used scintigraphy for the early detection of potential pseudarthroses in scoliotic patients at 6 months postoperatively. ${ }^{50}$ Of their 110 patients, $65 \%$ had uniform uptake at the fusion site, of which 1 had failed fusion based on surgical exploration. Based on these findings, the use of scintigraphy for the early detection of pseudarthrosis is not indicated since metabolic bone activity can be present in both immature arthrodesis and pseudarthrosis.
PET detects gamma ray emission indirectly from a positron-emitting radioactive tracer, such as fluorodeoxyglucose (FDG), to create a 3D image. FDG tracers have an affinity for metabolically active cells, and thus have traditionally been used to detect bone neoplasms and infections. ${ }^{33}$ More recently, it has been suggested that these tracers can be used to measure bone graft healing by correlating increased radioisotope uptake at the fusion site with increased woven bone formation and bone remodeling. ${ }^{20}$ Foldager et al. were able to demonstrate that PET is a valid imaging modality for monitoring active bone formation in vivo in their porcine anterior lumbar interbody fusion (ALIF) model. ${ }^{20}$ Using PET data, the authors derived calculations for bone metabolic activity based on the amount of PET tracer (FDG) incorporated into bone during formation.

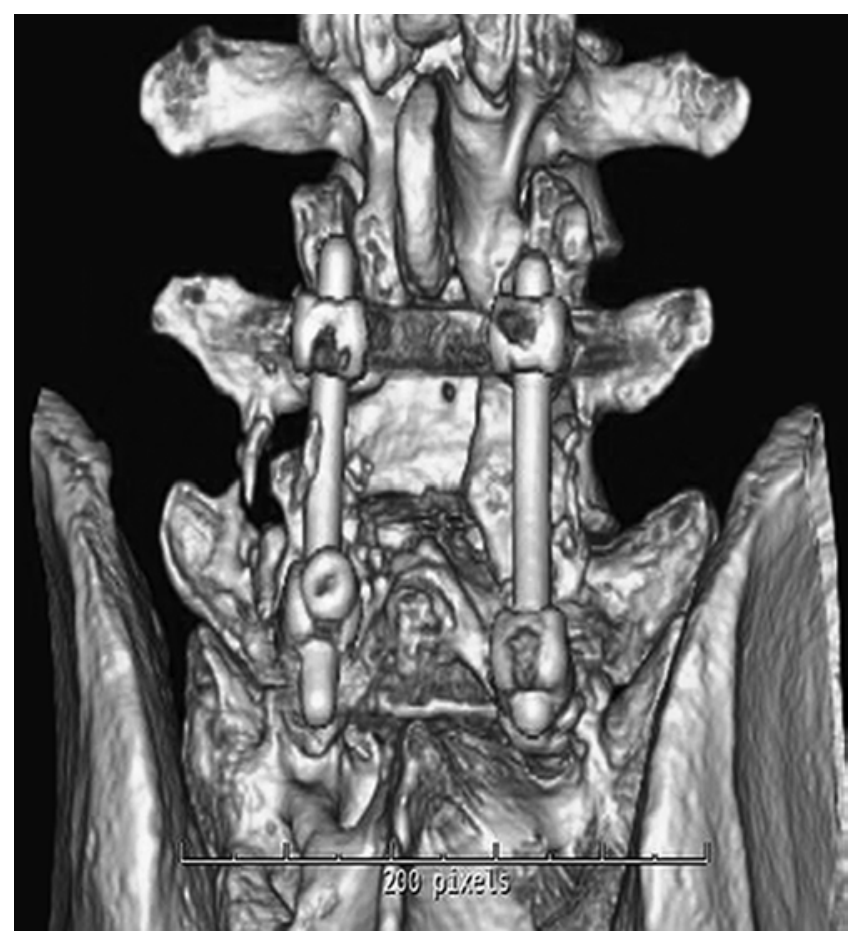

FIG. 4. Three-dimensional CT scan illustrating posterolateral pseudarthrosis with the failure of solid bone formation between the L- 4 and L-5 transverse processes bilaterally. 


\section{Surgical Strategies}

A total of 142 articles were found using the Embase and MEDLINE Ovid database: 132 articles were reviewed for inclusion and exclusion criteria. Ultimately, 8 articles $^{3,12,21,32,38,47,58,60}$ were included that compared the fusion rates after various surgical techniques for the treatment of degenerative lumbar disease requiring spinal fusion.

After the diagnosis of pseudarthrosis, depending on the clinical situation, there are many different treatment options. The primary principles include stabilization of the existing posterior fixation by replacing the loose fixation points, which is followed by regrafting. ${ }^{44}$ Zdeblick demonstrated that patients undergoing lumbosacral fusion for degenerative spine conditions had significantly higher fusion rates if they underwent combined autogenous bone graft with a rigid pedicle screw/rod fixation system versus autogenous bone graft only. ${ }^{60}$

Another attractive option would be to consider interbody fusion in the setting of posterolateral lumbar nonunion. Anterior lumbar interbody fusion (ALIF), posterior lumbar interbody fusion (PLIF), and lateral lumbar interbody fusion techniques have become popular surgical alternatives or adjuncts to posterolateral fusion (PLF). In some studies, the placement of graft material between adjacent vertebral bodies has shown higher fusion rates when compared with PLF (Table 2). ${ }^{51}$ The increased surface area under compressive forces provides a healthier biological environment than the intertransverse area. Christensen et al. reported fusion rates with ALIF as significantly higher than with PLF + pedicle screw fixation (92\% vs $80 \%$ respectively, $\mathrm{p}<0.04$ ). ${ }^{12}$ This technique would also potentially avoid revision scar formation and pain from a posterior approach. Furthermore, Kim et al. demonstrated that while additional PLF can be an option during interbody fusion, the combination PLF plus interbody fusion procedure was unlikely to improve outcomes more than just interbody fusion alone. ${ }^{38}$ Improved fusion rates with interbody fusion technique have been reported in other studies as well (Table 2)..$^{15,21,32,47,58}$

\section{Discussion}

Pseudarthrosis should be suspected when a fusion patient presents with recurrent pain and/or neurological symptoms during the long-term follow-up period. The mechanical exacerbation of symptoms may also accompany pain that indicates instability at the surgery site. Diagnosis can be challenging as these symptoms are not necessarily specific for pseudarthrosis but can be attributed to other possible etiologies such as infection or adjacent segment disease. A focused history and physical examination should be used to document any postoperative pain-free or pain-relief interval after the index procedure. While the physical examination is generally nonspecific, there may be a spinal deformity present due to the loss of anatomical correction and alignment secondary to fusion failure. . $^{28,41,44,46,52} \mathrm{~A}$ patient who denies any significant symptom relief postoperatively should be studied further to rule out differential diagnoses.

Open surgical exploration is the gold standard for lumbar fusion assessment as it allows the direct visualization of bone fusion. However, for patients with clinically suspected pseudarthrosis, several imaging modalities can be used. The most common radiographic findings suggestive of pseudarthrosis are implant failure or loss of fixation, radiolucencies, and deformity. ${ }^{18,28,39}$ Plain radiography and CT scanning are the most common imaging modalities used to diagnose lumbar pseudarthrosis. ${ }^{5,13}$ However, there

TABLE 2. Comparison of lumbar fusion techniques and fusion success rates

\begin{tabular}{lllc}
\hline \multicolumn{1}{c}{ Authors \& Year } & & Lumbar Fusion Technique & $\begin{array}{c}\text { Fusion } \\
\text { Success }\end{array}$ \\
\hline Zdeblick, 1993* & SDD, spondylolisthesis & PLF alone & $65 \%$ \\
& & PLF + semi-rigid instrumentation & $77 \%$ \\
& & PLF + rigid instrumentation & $95 \%$ \\
\hline Christensen et al., 2002* & Degenerative lumbar disease & PLF + rigid instrumentation & $80 \%$ \\
& & ALIF + PLF + rigid instrumentation & $92 \%$ \\
\hline Madan \& Boeree, 2003 & Degenerative lumbar disease & ALIF + cage instrumentation & $94.3 \%$ \\
& & PLIF + PLF & $100 \%$ \\
\hline Kim et al., 2006 & Degenerative lumbar disease & PLF + rigid instrumentation & $92 \%$ \\
& & PLF + PLIF + rigid instrumentation & $95 \%$ \\
& & PLIF + rigid instrumentation & $96 \%$ \\
\hline Strube et al., 2012 & DDD, facet joint arthritis & ALIF & $70.6 \%$ \\
& & APLF & $68.7 \%$ \\
\hline Høy et al., 2013 & Degenerative lumbar disease & PLIF + rigid instrumentation & $88 \%$ \\
& & TLIF + rigid instrumentation & $94 \%$ \\
\hline Berjano et al., 2015 & DDD, spondylolisthesis, scoliosis, stenosis, revision & XLIF & $87.1 \%$ \\
& other & & $84 \%$ \\
\hline Fujimori et al., 2015 & Degenerative spondylolisthesis & PLF + rigid instrumentation & TLIF + rigid instrumentation \\
\hline
\end{tabular}

APLF = anteroposterior lumbar fusion; $\mathrm{DDD}=$ degenerative disc disease; $\mathrm{TLIF}=$ transforaminal interbody fusion; $\mathrm{XLIF}=$ extreme lateral interbody fusion.

* A statistically significant difference was noted between surgical groups. 
remains some controversy regarding how much degree of motion is used to define successful versus failed bone fusion after surgery.,49 The US FDA's radiographic guidelines for successful lumbar fusion include less than $3 \mathrm{~mm}$ of translational motion and less than $5^{\circ}$ of angular motion on flexion and extension radiographs..$^{28}$

Furthermore, despite improved accuracy, CT scanning has significant limitations such as cost and radiation exposure. The radiation exposure from 1 lumbar spine CT has been deemed equivalent to approximately 240 chest radiographs. ${ }^{4}$ Subsequently, with a 16 -slice quantitative CT scan, the cancer risk has been estimated to be 1 in 200,000 compared with 1 in $1,000,000$ seen with plain chest radiography. While protocol modifications that reduce the exposure area can reduce the patient's cancer risk, ${ }^{53}$ the use of alternative imaging modalities continues to be investigated.

Interbody fusion techniques are promising as both preventive measures and treatments of lumbar pseudarthrosis. The use of interbody devices allows for increased surface area under compressive forces, thereby providing a more ideal environment for fusion. Furthermore, the surgical approach avoids midline scar formation that can be problematic should there be a need for reoperation..$^{55}$

Surgical outcomes after revision surgery for lumbar pseudarthrosis have unpredictable functional results..$^{10,40}$ Glassman et al. stratified outcomes based on the preoperative diagnoses of 327 patients who underwent decompression and PLF with instrumentation. Analysis of their patient-reported outcome measures found that the least amount of improvement, based on the Oswestry Disability Index at the 2-year follow-up, was seen in patients with the nonunion of a prior fusion (5.5 points). ${ }^{23}$ Furthermore, Dede et al. established that the outcomes after revision surgery for lumbar pseudarthrosis were associated with the primary diagnosis for initial fusion surgery. Their retrospective chart review of patients with either a primary diagnosis of degenerative disc disease or spondylolisthesis found that despite the high fusion rates after revision, the self-reported clinical outcomes were worse in patients with degenerative disc disease. ${ }^{14}$

Recent improvements in lumbar fusion rates can further be attributed to improved biologics, instrumentation, and understanding of local biology. Over the past few decades, the field has been introduced to various biologics that aid in spine arthrodesis, including allograft material, ceramics, and growth factor augmentations. The ideal biologic demonstrates osteoinductive, osteoconductive, and/or osteogenic properties that enhance bony fusion in the surgical bed while minimizing morbidity. Autografts, which are typically obtained from the anterosuperior aspect of the iliac crest, have traditionally been considered the gold standard for bone graft materials. However, complications from iliac crest bone graft harvesting ${ }^{36}$ and limitations in quantity have made the development of other potential bone graft alternatives attractive.

When comparing the efficacies of various biologics, a systematic review of posterolateral lumbar fusion rates reported an iliac crest bone graft fusion rate of $79 \%$ compared with 52\% with allograft alone, $87 \%$ with ceramics, $89 \%$ with demineralized bone matrices, $74 \%$ with autol-
TABLE 3. Efficacy of various osteobiologics for promoting lumbar arthrodesis*

\begin{tabular}{lc}
\hline \multicolumn{1}{c}{ Bone Graft Material } & Fusion Rate \\
\hline Autologous ICBG & $79 \%$ \\
\hline Local autograft alone & $89 \%$ \\
\hline Allograft alone & $52 \%$ \\
\hline Bone marrow aspirate & $85 \%$ \\
\hline BMP-2 & $94 \%$ \\
\hline Ceramics $\dagger$ & $87 \%$ \\
\hline DBM & $89 \%$ \\
\hline Autologous growth factor $\dagger$ & $74 \%$ \\
\hline
\end{tabular}

BMP-2 = bone morphogenetic protein-2; DBM = demineralized bone matrices; ICBG = iliac crest bone graft.

* Data obtained from Hsu et al., 2012.34

$\dagger$ Used as a bone graft extender.

ogous bone marrow, and 94\% with bone morphogenetic proteins (Table 3). ${ }^{34}$ While the reporting methods of the publications included from this review varied, these reported fusion rates suggest a benefit from the proper use of bone graft extenders and substitutes.

Another critical aspect of pseudarthrosis prevention is the preoperative assessment of the patient's condition, including identifying risk factors such as older age, osteoporosis, alcoholism, malnutrition, excessive motion at the cervicothoracic and/or thoracolumbar junctions, and cigarette smoking. A number of studies have shown cigarette smoking to be associated with increased rates of pseudarthrosis. ${ }^{8,9,29}$ Once considered to be an effect from nicotine, the exact mechanism by which cigarette smoke inhibits bone healing is currently still unclear. ${ }^{25} \mathrm{~A}$ recent study potentially implicates the inhibitory effects of 2,3,7,8-tetrachlorodibenzo- $p$-dioxin (TCDD), a halogenated aromatic hydrocarbon found in high levels in cigarette smoke. TCDD is a known aryl hydrocarbon receptor agonist that has been shown to reduce osteoblast formation and bone metabolism in vitro. ${ }^{54}$ When administered in a rat posterolateral fusion model, TCDD exposure significantly reduced fusion rates compared with controls. Future studies are necessary to further elucidate the effects of environmental contaminants on bone healing and formation.

\section{Conclusions}

Pseudarthrosis is a well-reported complication of lumbar spine fusion. Its diagnosis is based on appropriate clinical history and imaging findings of deformity, radiolucencies, implant failure, or loss of fixation. However, the radiographic presentation of pseudarthrosis is unpredictable as it can present up to a decade postoperatively despite the presence of solid bone formation at earlier time points. While plain radiographs and CT are the most common imaging modalities used, the use of other modalities with greater sensitivity and reduced radiation exposure continue to be investigated. The best treatment for pseudarthrosis is to prevent it from occurring after the initial operation. Improvements in bone graft materials, instrumentation, and surgical technique have all contributed to better fusion rates. These factors have also improved the surgical 
treatment and outcomes of pseudarthrosis revision surgeries. The use of interbody cages may promote better longterm fusion stability and improve patient-reported outcomes. To ensure the best surgical outcome after revision surgery, the surgeon must have a comprehensive and thorough understanding of the patient's preclinical diagnosis, expectations, and cause of pseudarthrosis prior to surgical intervention.

\section{References}

1. Adogwa O, Verla T, Thompson P, Penumaka A, Kudyba K, Johnson K, et al: Affective disorders influence clinical outcomes after revision lumbar surgery in elderly patients with symptomatic adjacent-segment disease, recurrent stenosis, or pseudarthrosis: clinical article. J Neurosurg Spine 21:153159,2014

2. Albert TJ, Pinto M, Smith MD, Balderston RA, Cotler JM, Park CH: Accuracy of SPECT scanning in diagnosing pseudoarthrosis: a prospective study. J Spinal Disord 11:197199, 1998

3. Berjano P, Langella F, Damilano M, Pejrona M, Buric J, Ismael M, et al: Fusion rate following extreme lateral lumbar interbody fusion. Eur Spine J 24 (Suppl 3):369-371, 2015

4. Biswas D, Bible JE, Bohan M, Simpson AK, Whang PG, Grauer JN: Radiation exposure from musculoskeletal computerized tomographic scans. J Bone Joint Surg Am 91:1882-1889, 2009

5. Blumenthal SL, Gill K: Can lumbar spine radiographs accurately determine fusion in postoperative patients? Correlation of routine radiographs with a second surgical look at lumbar fusions. Spine (Phila Pa 1976) 18:1186-1189, 1993

6. Bohnsack M, Gossé F, Rühmann O, Wenger K: The value of scintigraphy in the diagnosis of pseudarthrosis after spinal fusion surgery. J Spinal Disord 12:482-484, 1999

7. Brodsky AE, Kovalsky ES, Khalil MA: Correlation of radiologic assessment of lumbar spine fusions with surgical exploration. Spine (Phila Pa 1976) 16 (6 Suppl):S261-S265, 1991

8. Brown CW, Orme TJ, Richardson HD: The rate of pseudarthrosis (surgical nonunion) in patients who are smokers and patients who are nonsmokers: a comparison study. Spine (Phila Pa 1976) 11:942-943, 1986

9. Bydon M, De la Garza-Ramos R, Abt NB, Gokaslan ZL, Wolinsky JP, Sciubba DM, et al: Impact of smoking on complication and pseudarthrosis rates after single- and 2-level posterolateral fusion of the lumbar spine. Spine (Phila Pa 1976) 39:1765-1770, 2014

10. Carpenter CT, Dietz JW, Leung KY, Hanscom DA, Wagner TA: Repair of a pseudarthrosis of the lumbar spine. A functional outcome study. J Bone Joint Surg Am 78:712-720, 1996

11. Choudhri TF, Mummaneni PV, Dhall SS, Eck JC, Groff MW, Ghogawala Z, et al: Guideline update for the performance of fusion procedures for degenerative disease of the lumbar spine. Part 4: radiographic assessment of fusion status. J Neurosurg Spine 21:23-30, 2014

12. Christensen FB, Hansen ES, Eiskjaer SP, Høy K, Helmig P, Neumann P, et al: Circumferential lumbar spinal fusion with Brantigan cage versus posterolateral fusion with titanium Cotrel-Dubousset instrumentation: a prospective, randomized clinical study of 146 patients. Spine (Phila Pa 1976) 27:2674-2683, 2002

13. Cleveland M, Bosworth DM, Thompson FR: Pseudarthrosis in the lumbosacral spine. J Bone Joint Surg Am 30A:302312,1948

14. Dede O, Thuillier D, Pekmezci M, Ames CP, Hu SS, Berven $\mathrm{SH}$, et al: Revision surgery for lumbar pseudarthrosis. Spine J 15:977-982, 2015
15. Dehoux E, Fourati E, Madi K, Reddy B, Segal P: Posterolateral versus interbody fusion in isthmic spondylolisthesis: functional results in 52 cases with a minimum follow-up of 6 years. Acta Orthop Belg 70:578-582, 2004

16. DePalma AF, Rothman RH: The nature of pseudarthrosis. Clin Orthop Relat Res 59:113-118, 1968

17. Deyo RA, Mirza SK, Martin BI, Kreuter W, Goodman DC, Jarvik JG: Trends, major medical complications, and charges associated with surgery for lumbar spinal stenosis in older adults. JAMA 303:1259-1265, 2010

18. Dickson DD, Lenke LG, Bridwell KH, Koester LA: Risk factors for and assessment of symptomatic pseudarthrosis after lumbar pedicle subtraction osteotomy in adult spinal deformity. Spine (Phila Pa 1976) 39:1190-1195, 2014

19. Fischgrund JS, Mackay M, Herkowitz HN, Brower R, Montgomery DM, Kurz LT: Degenerative lumbar spondylolisthesis with spinal stenosis: a prospective, randomized study comparing decompressive laminectomy and arthrodesis with and without spinal instrumentation. Spine (Phila Pa 1976) 22:2807-2812, 1997

20. Foldager C, Bendtsen M, Zou X, Zou L, Olsen AK, Munk OL, et al: ISSLS prize winner: positron emission tomography and magnetic resonance imaging for monitoring interbody fusion with equine bone protein extract, recombinant human bone morphogenetic protein-2, and autograft. Spine (Phila Pa 1976) 33:2683-2690, 2008

21. Fujimori T, Le H, Schairer WW, Berven SH, Qamirani E, Hu SS: Does transforaminal lumbar interbody fusion have advantages over posterolateral lumbar fusion for degenerative spondylolisthesis? Global Spine J 5:102-109, 2015

22. Ghiselli G, Wharton N, Hipp JA, Wong DA, Jatana S: Prospective analysis of imaging prediction of pseudarthrosis after anterior cervical discectomy and fusion: computed tomography versus flexion-extension motion analysis with intraoperative correlation. Spine (Phila Pa 1976) 36:463-468, 2011

23. Glassman SD, Carreon LY, Djurasovic M, Dimar JR, Johnson JR, Puno RM, et al: Lumbar fusion outcomes stratified by specific diagnostic indication. Spine J 9:13-21, 2009

24. Gologorsky Y, Knightly JJ, Chi JH, Groff MW: The Nationwide Inpatient Sample database does not accurately reflect surgical indications for fusion. J Neurosurg Spine 21:984993, 2014

25. Gotfredsen K, Lindh CH, Berglundh T: Does longstanding nicotine exposure impair bone healing and osseointegration? An experimental study in rabbits. J Biomed Mater Res B Appl Biomater 91:918-923, 2009

26. Gray DT, Deyo RA, Kreuter W, Mirza SK, Heagerty PJ, Comstock BA, et al: Population-based trends in volumes and rates of ambulatory lumbar spine surgery. Spine (Phila Pa 1976) 31:1957-1964, 2006

27. Grubb SA, Lipscomb HJ, Suh PB: Results of surgical treatment of painful adult scoliosis. Spine (Phila Pa 1976) 19:1619-1627, 1994

28. Gruskay JA, Webb ML, Grauer JN: Methods of evaluating lumbar and cervical fusion. Spine J 14:531-539, 2014

29. Hadley MN, Reddy SV: Smoking and the human vertebral column: a review of the impact of cigarette use on vertebral bone metabolism and spinal fusion. Neurosurgery 41:116124, 1997

30. Heggeness MH, Esses SI: Classification of pseudarthroses of the lumbar spine. Spine (Phila Pa 1976) 16 (8 Suppl):S449S454, 1991

31. Herkowitz HN, Sidhu KS: Lumbar spine fusion in the treatment of degenerative conditions: current indications and recommendations. J Am Acad Orthop Surg 3:123-135, 1995

32. Høy K, Bünger C, Niederman B, Helmig P, Hansen ES, Li H, et al: Transforaminal lumbar interbody fusion (TLIF) versus posterolateral instrumented fusion (PLF) in degenerative 
lumbar disorders: a randomized clinical trial with 2-year follow-up. Eur Spine J 22:2022-2029, 2013

33. Hsu W, Hearty TM: Radionuclide imaging in the diagnosis and management of orthopaedic disease. J Am Acad Orthop Surg 20:151-159, 2012

34. Hsu WK, Nickoli MS, Wang JC, Lieberman JR, An HS, Yoon ST, et al: Improving the clinical evidence of bone graft substitute technology in lumbar spine surgery. Global Spine J 2:239-248, 2012

35. Kanemura T, Matsumoto A, Ishikawa Y, Yamaguchi H, Satake K, Ito Z, et al: Radiographic changes in patients with pseudarthrosis after posterior lumbar interbody arthrodesis using carbon interbody cages: a prospective five-year study. J Bone Joint Surg Am 96:e82, 2014

36. Kannan A, Dodwad SN, Hsu WK: Biologics in spine arthrodesis. J Spinal Disord Tech 28:163-170, 2015

37. Kant AP, Daum WJ, Dean SM, Uchida T: Evaluation of lumbar spine fusion. Plain radiographs versus direct surgical exploration and observation. Spine (Phila Pa 1976) 20:2313-2317, 1995

38. Kim KT, Lee SH, Lee YH, Bae SC, Suk KS: Clinical outcomes of 3 fusion methods through the posterior approach in the lumbar spine. Spine (Phila Pa 1976) 31:1351-1358, 2006

39. Kim YJ, Bridwell KH, Lenke LG, Cho KJ, Edwards CC II, Rinella AS: Pseudarthrosis in adult spinal deformity following multisegmental instrumentation and arthrodesis. J Bone Joint Surg Am 88:721-728, 2006

40. Kornblum MB, Fischgrund JS, Herkowitz HN, Abraham DA, Berkower DL, Ditkoff JS: Degenerative lumbar spondylolisthesis with spinal stenosis: a prospective long-term study comparing fusion and pseudarthrosis. Spine (Phila Pa 1976) 29:726-734, 2004

41. Kullar R, Klineberg E, Gupta M: Complications: pseudoarthrosis/nonunion, in Patel VV, Patel A, Harrop JS, et al. (eds): Spine Surgery Basics. Berlin: Springer, 2014, pp 533-540

42. Laasonen EM, Soini J: Low-back pain after lumbar fusion. Surgical and computed tomographic analysis. Spine (Phila Pa 1976) 14:210-213, 1989

43. Lang P, Genant HK, Steiger P, Chafetz N, Morris JM: [3-dimensional computed tomography and multiplanar CT-reformations in lumbar spondylodesis.] Rofo 148:524-529, 1988 (Ger)

44. Larsen JM, Capen DA: Pseudarthrosis of the lumbar spine. J Am Acad Orthop Surg 5:153-162, 1997

45. Larsen JM, Rimoldi RL, Capen DA, Nelson RW, Nagelberg $\mathrm{S}$, Thomas JC Jr: Assessment of pseudarthrosis in pedicle screw fusion: a prospective study comparing plain radiographs, flexion/extension radiographs, CT scanning, and bone scintigraphy with operative findings. J Spinal Disord 9:117-120, 1996

46. Lee YP, Sclafani J, Garfin SR: Lumbar pseudarthrosis: diagnosis and treatment. Semin Spine Surg 23:275-281, 2011

47. Madan SS, Boeree NR: Comparison of instrumented anterior interbody fusion with instrumented circumferential lumbar fusion. Eur Spine J 12:567-575, 2003

48. Mardjetko SM, Connolly PJ, Shott S: Degenerative lumbar spondylolisthesis. A meta-analysis of literature 1970-1993. Spine (Phila Pa 1976) 19 (20 Suppl):2256S-2265S, 1994

49. McAfee PC, Boden SD, Brantigan JW, Fraser RD, Kuslich SD, Oxland TR, et al: Symposium: a critical discrepancy-a criteria of successful arthrodesis following interbody spinal fusions. Spine (Phila Pa 1976) 26:320-334, 2001

50. McMaster MJ, Merrick MV: The scintigraphic assessment of the scoliotic spine after fusion. J Bone Joint Surg Br 62B:65-72, 1980

51. Mummaneni PV, Dhall SS, Eck JC, Groff MW, Ghogawala $\mathrm{Z}$, Watters WC III, et al: Guideline update for the performance of fusion procedures for degenerative disease of the lumbar spine. Part 11: interbody techniques for lumbar fusion. J Neurosurg Spine 21:67-74, 2014

52. Raizman NM, O'Brien JR, Poehling-Monaghan KL, Yu WD: Pseudarthrosis of the spine. J Am Acad Orthop Surg 17:494-503, 2009

53. Richards PJ, George J, Metelko M, Brown M: Spine computed tomography doses and cancer induction. Spine (Phila Pa 1976) 35:430-433, 2010

54. Rothem DE, Rothem L, Soudry M, Dahan A, Eliakim R: Nicotine modulates bone metabolism-associated gene expression in osteoblast cells. J Bone Miner Metab 27:555-561, 2009

55. Salehi SA, Tawk R, Ganju A, LaMarca F, Liu JC, Ondra SL: Transforaminal lumbar interbody fusion: surgical technique and results in 24 patients. Neurosurgery 54:368-374, 2004

56. Shah RR, Mohammed S, Saifuddin A, Taylor BA: Comparison of plain radiographs with CT scan to evaluate interbody fusion following the use of titanium interbody cages and transpedicular instrumentation. Eur Spine J 12:378-385, 2003

57. Stauffer RN, Coventry MB: Anterior interbody lumbar spine fusion. Analysis of Mayo Clinic series. J Bone Joint Surg Am 54:756-768, 1972

58. Strube P, Hoff E, Hartwig T, Perka CF, Gross C, Putzier M: Stand-alone anterior versus anteroposterior lumbar interbody single-level fusion after a mean follow-up of 41 months. J Spinal Disord Tech 25:362-369, 2012

59. Taylor VM, Deyo RA, Cherkin DC, Kreuter W: Low back pain hospitalization. Recent United States trends and regional variations. Spine (Phila Pa 1976) 19:1207-1212, 1994

60. Zdeblick TA: A prospective, randomized study of lumbar fusion. Preliminary results. Spine (Phila Pa 1976) 18:983-991, 1993

\section{Disclosure}

Dr. Hsu reports that he serves on the advisory boards for Medtronic, Bacterin, Lifenet, Globus, Stryker, and Bioventus and works as a consultant for Bacterin, Relievant, Ceramtec, Medtronic, Stryker, Globus, Bioventus, and Graftys. Dr. Baker reports that has contracts and/or receives grants from Arthrex Inc., K2M, Depuy-Synthes, DJO Global, Stryker Trauma, Zimmer, AOSpine North America, AO Foot \& Ankle Society, AO Society for Sports Medicine, Cervical Spine Research Society, and the US Army/CDMRP.

\section{Author Contributions}

Conception and design: all authors. Acquisition of data: Chun. Analysis and interpretation of data: Chun. Drafting the article: Chun. Critically revising the article: all authors. Reviewed submitted version of manuscript: all authors. Administrative/techni$\mathrm{cal} /$ material support: Chun. Study supervision: Hsu, Baker.

\section{Correspondence}

Wellington K. Hsu, Department of Orthopaedic Surgery, Northwestern University Feinberg School of Medicine, 676 N. St. Clair St., \#1350, Chicago, IL 60611. email: whsu@nm.org. 